the clinical implications of their subjects, would be entirely wrong.

Devaluing our national assets is a particularly British habit. Both the citation indices and the comments which reach me from all over the world confirm that the British Journal of Psychiatry is highly regarded by psychiatrists and research scientists everywhere. It is certainly open to improvement, though, and constructive comments would be welcomed, but to say that most members "do little more than glance at it" is neither fair nor accurate.

Hugh FreemaN

Editor

British Journal of Psychiatry

\section{Multiple personality disorder}

\section{Dear Sirs}

I can quite understand the plight of Lynn A. Gold looking for patients with multiple personality disorder (Psychiatric Bulletin, April 1989, 13, 202).

I have practised for the past 14 years in rural hospitals and urban teaching centres in Sri Lanka, UK, and Canada and not yet come across a single person with multiple personality disorder. A simple explanation is either I am not clever enough to detect these species or they do not exist in this world. I have asked numerous psychiatric colleagues of mine if they have come across multiple personality disorders, and the answer has always been in the negative. However, it's stated in the DSM-III as a diagnostic entity and I will continue to keep my eyes open and if I do have the luck to come across this category I will certainly inform Lynn Gold.

\section{Metropolitan General Hospital}

LAL Fernando

\title{
Bovine spongiform encephalophathy
}

DeAr SIRS

Does the College consider that it should lobby the Ministry of Agriculture and also the Ministry of Health on the subject of (BSE) bovine spongiform encephalopathy?

Sir Richard Southwood's report stated that the possibility of this disease being transmitted to humans is "remote". Since this disease seems to be so similar to Creuzfeldt Jakob Disease, any possibility, however remote, of its being transmitted should strike terror into the heart of anyone who has ever eaten a sausage.

The authorities have seen fit to legislate about what meat products can be put into baby foods, but not food for adults. Is this logical? If they have worry about these products, neither babies nor adults should be placed at risk. An epidemic of Creuzfeldt Jakob Disease would surely rival Aids in the devastation it could cause to families who have innocently eaten sausage or meat pies.

High Ground

A. Glavina

Manesty, Keswick

Cumbria CA12 5UG 